\title{
COMPORTAMENTO DO CONSUMIDOR EM MERCADOS FORMAIS E INFORMAIS: VALORES DE COMPRA HEDÔNICO E UTILITÁRIO
}

\section{RESUMO}

Embora haja grande quantidade de trabalhos voltados ao estudo dos mercados formais, poucas pesquisas versam diligência à análise dos mercados informais. Ainda mais insípido é o corpo teórico constituído pelos estudos referentes à comparação desses ambientes. Destarte, esta pesquisa objetivou analisar e comparar o comportamento de consumidores de mercados formais e informais, representados por um pequeno varejo e uma feira livre, respectivamente, à luz dos valores de compra hedônico e utilitário. Para tal, serão

Felipe Gerhard

Mestrando em Administração

- UECE- Fortaleza-CE-BR

<felipegerhard.rns@gmail. com>

Lucas Lopes Ferreira de Souza

Mestrando em Administração

- UECE - Fortaleza-CE-BR

$<$ lucaslfsouza@hotmail. com>

Thiago Matheus de

Paula Sousa

Graduando em Ciências

Econômicas - UFC

- Fortaleza-CE-BR <

thiagomatheus.rns@gmail.

com>

Verónica Peñaloza

Doutora em Economia USP e professora mestrado UECE - Fortaleza-CE-BR $<$ veronica.penaloza@uece. br> examinados e comparados os valores de compra dos consumidores de ambos os ambientes. Mediante a aplicação de uma survey, foram examinados os valores de compra dos consumidores desses ambientes e, utilizando-se as técnicas estatísticas AFE e ANOVA, compararam-se tais valores. Os resultados obtidos corroboram as hipóteses de pesquisa levantadas, porquanto revelam que os consumidores de mercados formais possuem valor de compra utilitário significantemente maior do que o apresentado pelos frequentadores de mercados informais. Por outro lado, os consumidores de mercados informais demonstraram valor de compra hedônico significantemente maior do que os clientes de mercados formais.

Palavras-chave: Mercados formais e informais. Comportamento do consumidor. Valor de compra hedônico e utilitário.

\section{INTRODUÇÃO}

Muito embora as pesquisas em mercados formais tenham se intensificado ao longo dos últimos anos, a frequência dos estudos acadêmicos versados ao mercado informal 
não tem demonstrado o mesmo crescimento (RAJAGOPAL, 2010b; PETRESCU; BHATLI, 2013). Ademais, é possível asseverar que o arcabouço teórico construído pelos trabalhos voltados a tal mercado ainda é muito insípido (RAJAGOPAL, 2010a; OZUDURU; VAROL; ERCOSKUN, 2012; PETRESCU; BHATLI, 2013).

Segundo o Banco Mundial (2000) a importância dos mercados informais é demonstrada por seus números, uma vez que, já no início da década passada, cerca de $40 \%$ de toda renda produzida pelas nações pobres e cerca de $17 \%$ do PIB dos países ricos advém dessa fonte. No Brasil, quase metade dos postos de trabalhos existentes é constituído por profissionais não registrados ou autônomos (ULYSSEA, 2006).

Os Mercados formal e informal estão indissociavelmente imbricados na economia moderna. Com efeito, segundo Goto e Mano (2012), a expansão do mercado informal está diretamente vinculada à redução do mercado formal; o mesmo ocorre com o número de empregos e volume de transações no mercado informal (ARBEX; FREGUGLIA; CHEIN, 2013; LOUREIRO; ARAUJO; SOUZA, 2013).

Cumpre observar ainda que, embora se tenha estudado os mercados formais e informais separadamente, pesquisas que analisem os dois ambientes simultaneamente são escassas na literatura versada ao tema (OZUDURU; VAROL; ERCOSKUN, 2012).

Dessa forma, esta pesquisa tem como objetivo analisar e comparar o comportamento de consumidores de mercados formais e informais, representados por um pequeno varejo e uma feira livre, à luz dos valores de compra hedônico e utilitário. Para tal, serão examinados e comparados os valores de compra dos consumidores de ambos os ambientes. Dessa forma, inicial- mente, mediante a aplicação de um survey, serão examinados os valores de compra dos consumidores desses ambientes e, por conseguinte, utilizando-se as técnicas estatísticas análise fatorial exploratória e ANOVA, serão comparados tais valores, observando-se as hipóteses levantadas por meio da análise da literatura.

Este artigo divide-se em cinco seções além desta introdução. Inicialmente, serão levantados os principais aspectos teóricos referentes aos valores de consumo hedônico e utilitário. Logo após, serão levantados dados e características atuais dos mercados formais e informais, bem como os mais importantes conceitos concernentes a seus representantes, ao pequeno varejo e à feira livre. Por conseguinte, serão observadas as principais propriedades metodológicas do trabalho. Em ato contínuo, analisar-se-ão os resultados obtidos na pesquisa de campo, comparando-se com os achados teóricos obtidos na literatura. Por fim, serão apresentadas as conclusões da pesquisa, assim como as limitações do artigo e sugestões para trabalhos futuros.

\section{CONSUMO HEDÔNICO E UTILITÁRIO}

Dentre os primeiros autores a abordarem o tema dos valores de consumo hedônico e utilitário destacam-se Holbrook e Hirschman (1982). Os autores definem como hedônico o valor de compra motivado por aspectos multissensoriais, motivos e fantasias do consumidor. Os produtos, caracterizados por desejos de consumo, passam a ser percebidos como símbolos subjetivos. A compra hedônica não traz consigo o sentido negativo de trabalho árduo, difícil de ser realizado (BABIN; DARDEN; GRI- 
FFIN, 1994; HAUSMAN, 2000). Dessa forma, está associada ao valor percebido da experiência de compra pelo consumidor, ou seja, fatores subjetivos que variam de acordo com o contexto de cada um (HAUSMAN, 2000). Para Rocha (2005), a dimensão hedônica se relaciona intimamente com o consumismo, desenvolvendo uma forma de promover a cultura de consumo, indissoluvelmente presente em nossa sociedade (BAURDILLARD, 2002).

Por outro lado, a dimensão utilitária de compra, que apresenta elementos distintos à dimensão hedônica de consumo, é relevante para consumidores que buscam o cumprimento de objetivos com menores riscos (BATRA; AHTOLA, 1991; BABIN; DARDEN; GRIFFIN, 1994). O valor de compra utilitário emerge quando, segundo Batra e Ahtola (1991), a compra é completada com sucesso e eficiência. Nesse sentido, afirmam os autores, o utilitarismo sobrevém de resultados relativamente tangíveis da experiência de compra, como uma aquisição eficiente de um produto. Portanto, o discurso utilitário é essencialmente racional e funcional, representando, pois, o trabalho de compra bem feito. O valor utilitário em uma compra é baseado na utilidade que esta possui para o consumidor, se o bem ou serviço demandado atende de fato às suas necessidades (BABIN; DARDEN; GRIFFIN, 1994).

Em síntese, a abordagem utilitária reporta-se a aspectos racionais, objetivos e econômicos, enquanto a hedônica foca-se em características psicológicas, simbólicas e emotivas do consumo (BABIN; DARDEN; GRIFFIN, 1994).

Contudo, quanto às características hedônicas ou utilitárias apresentadas pelo consumidor, cabe ser feita uma ressalva. Vale destacar que é possível a uma mesma pessoa apresentar inclinações tanto ao valor hedônico quanto ao utilitário, uma vez que, embora apresentem propriedades distintas, não são características excludentes (BABIN; DARDEN; GRIFFIN, 1994; LOPES et al., 2010).

\section{MERCADO FORMAL E INFORMAL}

Mercados informais estão presentes em todo o mundo. Contudo, em economias emergentes, tais mercados possuem uma amplitude ainda maior (GOTO; MANO, 2012; ARBEX; FREGUGLIA; CHEIN, 2013). Segundo Schneider e Enste (2002), o tamanho do mercado informal varia de um quarto do produto interno bruto (PIB) em países em desenvolvimento como Brasil, Chile e Colômbia, a quase três quartos como países como Nigéria, Egito e Tailândia. De acordo com o Banco Mundial (2000), a parcela da economia representada pelo mercado informal já representava no início da década passada cerca de $40 \%$ da renda produzida por nações pobres e cerca de $17 \%$ do PIB de países ricos. No Brasil, quase a metade dos empregos existentes é constituído por profissionais não registrados ou autônomos (ULYSSEA, 2006). Dessa forma, observa-se a importância desse mercado para a economia.

Embora os mercados informais venham sendo objeto de estudo em diversas ciências, a escassez de publicações e de dados confiáveis tem limitado as investigações teóricas a analisarem, principalmente, possíveis intervenções públicas em tais locais (GOTO; MANO, 2012). Ainda que tenha sido historicamente associado à clandestinidade e a imperfeições econômicas, o mercado informal consegue suplementar seus defeitos apresentando características 
positivas importantes para seus frequentadores, tais como vínculos sociais, raízes culturais e preços baixos (SHERRY, 1990a, 1990b; LUKE; MUNSHI; ROSENZWEIG, 2004; WAHBA; ZENOU, 2005; RAJAGOPAL, 2010b).

Enquanto o mercado formal apresenta uma frieza no relacionamento com o cliente, no mercado informal os vínculos desenvolvidos com os consumidores são acentuados, o que proporciona a tais mercados uma vantagem competitiva frente aos seus concorrentes formais, uma vez que possibilita a criação de uma relação de amizade entre vendedores, clientes e entre os próprios frequentadores (SHERMAN; MCCROHAN; SMITH, 1985; RAJAGOPAL, 2010a). A relação entre os mercados formal e informal apresenta ainda outras peculiaridades. Segundo Goto e Mano (2012), o mercado informal expande quando uma redução do mercado formal é verificada. Da mesma forma, o número de empregos no mercado informal, assim como o volume de transações, cresce influenciado pelo ciclo de crises observado no mercado formal (LOUREIRO; ARAUJO; SOUZA, 2013; ARBEX; FREGUGLIA; CHEIN, 2013).

Nesta pesquisa, será considerado como representante de mercados formais o pequeno varejo, uma vez que, segundo Sampaio et al. (2009) e Hernandez (2009), os consumidores de tais locais apresentam características de compra marcadamente utilitária. A feira livre, por outro lado, será considerada a representante dos mercados informais, dado que, segundo Sherry (1990b), seus consumidores demonstram um destacado valor de consumo hedônico. A seguir são levantados os principais aspectos teóricos desses locais.

\subsection{PEQUENO VAREJO}

Segundo Levy e Weitz (2004), varejo seria um conjunto de atividades organizadas que agregam valor a produtos e/ ou serviços ofertados a consumidores para seu uso pessoal ou familiar. Brito, Vieira e Espartel (2011) destacam a importância do varejo ao caracterizá-lo como um campo de grande amplitude, posicionando-o como um setor que inclui uma grande diversidade de produtos e serviços ofertados, além de uma extensa cadeia de suprimentos e de inúmeros canais de distribuição.

No Brasil o setor varejista é responsável por grande parte da comercialização de bens (TERRA, 2004). Segundo Fávero (2004), supermercados (exemplo de empresa do setor varejista) vêm expandindo, ao longo das últimas décadas, os seus ramos de atuação e ampliando o sortimento dos produtos oferecidos. O autor acrescenta que as atividades do comércio varejista, outrora restritas à comercialização de produtos básicos, como alimentação, higiene e limpeza, estão sendo expandidas para outros segmentos, como os voltados a bens duráveis, semiduráveis, têxteis, entre outros.

Muito embora os estabelecimentos varejistas estejam cada vez mais preocupados com o ambiente do interior de loja (GATTO, 2002; ZORILLA, 2002; FEIJÓ; BOTELHO, 2012), a dimensão utilitária de consumo ainda prevalece como lógica dominante no pequeno varejo (SAMPAIO et al., 2009). Segundo Hernandez (2009), o valor utilitário de compra é predominante entre os consumidores de comércios varejistas, uma vez que razões como localização, preço e disponibilidade de estoque são os principais motivos apontados pelos clientes para se escolher tais locais 
de compra. Da mesma forma, Sampaio et al. (2009) apontam razões como facilidade de se encontrar um produto que se procura (decorrente de um desenho funcional da loja), receber um serviço necessário por algum funcionário ou adquirir uma informação útil. Logo, observa-se, igualmente, que as razões elencadas pelo autor também se inserem dentro do espectro compreendido pelo valor utilitário de compra, porquanto se relacionam com a consecução de uma compra com objetividade e eficiência, buscando-se otimizar o tempo e o dinheiro gasto em uma transação econômica.

Assim como salientado por Hernandez (2009) e Sampaio et al. (2009), o preço do produto é destacado por Luppe e Angelo (2010) como um dos fatores mais relevantes para a escolha de determinado estabelecimento varejista. $\mathrm{O}$ fator, segundo os autores, é um dos principais parâmetros de comparação entre estabelecimentos comerciais. Com efeito, associa-se estritamente ao valor de compra utilitário.

De forma análoga, outro fator imprescindível para a escolha de um estabelecimento varejista é a sua localização. Por meio da técnica de mapeamento de clientes, Applebaum (1966) foi um dos primeiros autores a tratar da importância da proximidade física para supermercados. Autores como Parente e Kato (2001) corroboram as acepções de Applebaum (1966) ao demonstrarem o destacado papel desempenhado pela boa localização na escolha de um local de compra. Segundo os autores, a maior parte das vendas de um pequeno varejo decorre de clientes que moram dentro de uma área geográfica relativamente pequena em torno da loja. Ademais, uma boa localização permite à empresa um melhor relacionamento com os seus clientes (APPLEBAUM, 1966).

\subsection{FEIRA LIVRE}

Mercados não tradicionais existem em todo o mundo, contudo, nas regiões menos desenvolvidas, esses centros de comércio, às vezes informais, fazem parte do cotidiano da população mais pobre e, frequentemente, são a única forma de acesso a produtos mais baratos, ao alcance de seu orçamento (SHERRY, 1990a). Além de constituírem a realidade diária de pessoas e cidades, as feiras livres tiveram uma importância fundamental para o nascimento dos primeiros povoados, destaca Pirenne (1997), pois exerceram um papel imprescindível no desenvolvimento das relações comerciais internas e entre diferentes localidades. Tais fatores impulsionaram os primeiros agrupamentos humanos a se transformarem em grandes centros urbanos.

O comportamento do consumidor nestes mercados também é diferente do comportamento do consumidor no mercado formal (BELK; SHERRY; WALLENDORF, 1988; SHERRY, 1990a, 1990b). No mercado informal, o comportamento do consumidor é menos padronizado e mais envolvente (perigoso ou excitante), a oportunidade de experimentar pode ser libertadora para alguns consumidores e ameaçadora para outros (BELK; SHERRY; WALLENDORF, 1988). Compradores mais frequentes desses mercados sentem que é divertido procurar pechinchas, percebem o serviço amigável e gostam da variedade de produtos disponíveis (BELK; SHERRY; WALLENDORF, 1988; SHERRY, 1990a, 1990b; RAJAGOPAL, 2010a, 2010b).

Funcionando em espaços abertos (geralmente praças ou ruas transversais) e obedecendo a uma periodicidade regular, as feiras são locais de circulação, distribui- 
ção e consumo de bens e serviços onde são comercializados muito mais do que gêneros alimentícios de primeira necessidade (PANDOLFO, 1987). As feiras nas regiões menos desenvolvidas oferecem ao consumidor de baixa renda opções de consumo não encontradas nos mercados tradicionais; vendem-se desde produtos usados até animais (MENEZES, 2005). E é neste mundo diverso, excêntrico e colorido, que o consumidor pode extravasar suas emoções de consumo; embora o caráter destes mercados seja eminentemente mercantil, eles funcionam também como centros culturais e de lazer, onde o consumo mostra todo o seu potencial hedônico (BELK; SHERRY; WALLENDORF, 1988; SHERRY, 1990a, 1990b; MENEZES, 2005; RAJAGOPAL, 2010a).

Menezes (2005, p. 12) vale-se da expressão polissemia urbana para designar as mais variadas manifestações das feiras, que abrigam "acontecimentos, encontros, seus personagens, suas mercadorias, seus ritos, sons, cores e cheiros, sua atualidade e atemporalidade que se conjugam formando enfim um complexo mosaico de contradições". O autor expõe a realidade da feira salientando a predominância da população menos abastada, atuando tanto como consumidores quanto como vendedores dentre as vielas da feira. Contudo, há uma miscelânea de agentes sociais interagindo a todo o momento, representando todos os tipos urbanos. Ademais, é facilmente perceptível a atuação de um componente transgressor na feira, pois, devido ao seu caráter díspar, caracteriza-se como uma resistência aos mercados formais, que preserva hábitos antigos e uma cultura atemporal própria.

As dimensões subsistência e diversão erigem o cotidiano da feira, os seus aspectos mais peculiares, as relações de amizade, a dinâmica de compra e venda, de escambo ou de barganha, as polissemias e polifonias, o medo, o pensamento rápido, o sol escaldante, o grito do vendedor ou o ruído ensurdecedor dos equipamentos eletrônicos, a procura por um item singular, a alegria, a profusão de mercadorias espalhadas por todo lado, tudo mediado pela sensação de pertencer a uma grande unidade coletiva (MENEZES, 2005).

As feiras possuem uma marcada dimensão festiva que se caracteriza, na visão dos próprios consumidores, pela existência de um senso de empolgação por haver centenas de pessoas e por poder vivenciar a empolgação alheia, em um ambiente a céu aberto e ainda com a oportunidade de observar diversos itens à venda e barganhá-los (SHERRY, 1990a, 1990b; RAJAGOPAL, 2010a). Menezes (2005) corrobora tais constatações, que suportam a fuga da racionalidade do consumo nos mercados informais, ao afirmar que algumas curiosas circunstâncias podem levar as pessoas à feira livre, principalmente as pertencentes a classes sociais mais abastadas, e dentre elas destacam-se: uma remota lembrança de suas infâncias interioranas, pois fazem emergir suas raízes rurais e as fazem percorrer os diversos corredores da feira com um forte sentimento nostálgico, ou a simples busca de alguma relíquia, fenômeno que Sherry (1990a) denomina de caça ao tesouro. Geralmente essas pessoas não buscam nas feiras bens relativos às suas subsistências, os quais poderiam ser mais confortavelmente adquiridos em shoppings ou em grandes cadeias de supermercados.

Dessa forma, conforme aduz as acepções teóricas supracitadas, versadas ao consumo em pequeno varejo e em feiras livres, é possível estruturar as seguintes hipóteses de pesquisa: 
H1: Os consumidores de feiras livres possuem um valor de consumo hedônico significantemente mais forte do que os consumidores de pequenos varejos;

H2: Os consumidores de pequenos varejos possuem um valor de consumo utilitário significantemente mais forte do que os consumidores de feiras livres.

\section{PROCEDIMENTOS METODOLÓGICOS}

A pesquisa quantitativa, realizada em forma de survey descritivo, pretendeu analisar o valor de compra dos consumidores de um pequeno varejo e uma feira livre, se hedônico e/ou utilitário, e obter informações sobre o perfil desses consumidores. O estudo foi realizado em duas etapas: a primeira em um pequeno varejo situado na periferia da cidade de Fortaleza e a segunda na feira da Parangaba, localizada na mesma cidade. O pequeno varejo é composto por dois sócios familiares, que também trabalham nas atividades operacionais da empresa, e seis funcionários que se dividem no horário de funcionamento da empresa, de 6:00 às 20:00, de segunda-feira ao sábado e nos domingo de 8:00 às 12:00. Embora possua mais de 10 anos de funcionamento, os atuais donos do estabelecimento adquiriram-no em 2011. Vale destacar que, após dois meses de pesquisas, praticamente se alcançou o número total de clientes que realizavam suas compras no próprio estabelecimento e se dispunham a responder o questionário.

Quanto à feira da Parangaba, cumpre salientar que, apesar de existir um cadastro dos comerciantes na Prefeitura, há centenas de ambulantes ilegais que superpovoam os seus espaços, vendendo todo tipo de quin- quilharia, que varia desde objetos pessoais até produtos ilícitos. Contudo, não há dados precisos sobre o número de consumidores que frequentam o local. Para melhorar a resposta do público, uma vez que no pré-teste constatou-se que havia pouca receptividade dos consumidores locais, foi oferecido um lanche que era consumido após o preenchimento do questionário.

A amostra da pesquisa é de natureza não probabilística por conveniência, assomando um total de 528 indivíduos; 227 respondentes no pequeno varejo e 301 na feira. A pesquisa em campo com os consumidores ocorreu no decorrer de várias semanas, durante os meses de janeiro a março de 2013. No pequeno varejo a pesquisa ocorreu dentre das 7:00 às 18:00 horas, período de maior afluência de público, e na feira no período de 7:00 às 14:00 horas, aos domingos.

Quanto à escala utilizada, observando-se a coexistência dos dois valores de compra, hedônico e utilitário, utilizou-se a escala criada por Babin, Darden e Griffin (1994), com o intuito de aferir a intensidade em que se apresentam no comportamento de compra dos consumidores nos locais de pesquisa.

$\mathrm{O}$ instrumento de pesquisa foi composto por duas partes. A primeira parte, com 13 questões, corresponde à escala de Babin, Darden e Griffin (1994), adaptada e replicada por Lopes et al. (2010), com consumidores brasileiros, em escala de Likert de 7 pontos variando entre: 1, discordo totalmente a 7 , concordo totalmente. A escala está formada por 13 itens, 7 variáveis hedônicas e 6 utilitárias, evidenciadas no Quadro 1, a seguir. 


\begin{tabular}{|ll}
\hline HED1 & Variáveis Hedônicas \\
\cline { 2 - 2 } HED2 & Eu fiz esta compra porque quis e não por obrigação; \\
HED3 & $\begin{array}{l}\text { Comparando com outras coisas que eu poderia ter feito, o tempo gasto comprando este produto } \\
\text { foi muito mais agradável; }\end{array}$ \\
HED4 & Esqueci os meus problemas enquanto estive no/a Mercadinho/Feira da Parangaba; \\
HED5 & Fazer esta compra foi uma verdadeira distração para mim; \\
HED6 & Estar no Mercadinho foi um jeito muito agradável de passar o tempo; \\
HED7 & A busca por este produto me deu um grande prazer. \\
\cline { 2 - 2 } & Variáveis Utilitárias \\
UTI1 & Eu fui eficiente ao fazer esta compra; \\
UTI2 & Eu gastei apenas o tempo necessário para fazer esta compra; \\
UTI3 & Eu fiz esta compra com rapidez; \\
UTI4 & Fazer esta compra foi como cumprir uma obrigação; \\
UTI5 & Foi fácil fazer esta compra porque eu sabia exatamente o que eu queria comprar; \\
UTI6 & O preço que paguei nesta compra compensou o tempo que gastei. \\
\hline
\end{tabular}

Quadro 1 - Variáveis hedônicas e utilitárias do instrumento de pesquisa

Fonte: Babin, Darden e Griffin (1994), adaptada por Lopes et al. (2010).

Quanto à segunda parte, realizaram-se perguntas de caráter socioeconômico, para averiguar-se o perfil do consumidor quanto à renda, escolaridade, dentre outros. Para a análise dos dados levantados, foram utilizadas, além dos módulos de estatística descritiva, as técnicas estatísticas de análise fatorial exploratória (HAIR et al., 2005) e ANOVA (MALHOTRA, 2001), porquanto a primeira técnica teve como objetivo analisar a estrutura subjacente erigida pela variância apresentada pelas questões de pesquisa e a segunda objetivou averiguar a divergência de variância entre as categorias e construtos estudados. Os métodos foram realizados com auxílio do "software" Statistical Package for the Social Sciences (SPSS) versão 20.0 .

\section{ANÁLISE DOS RESULTADOS}

Com o objetivo de examinar o comportamento dos clientes, tanto de um pequeno estabelecimento varejista quanto de uma feira livre, foram analisados os seus valores de consumo no que concerne às dimensões de compra hedônica e utilitária. De forma análoga, também foi averiguado o perfil socioeconômico dos respondentes, descrito a seguir na Tabela 1 . 
Tabela 1 - Dados demográficos

\begin{tabular}{lccc}
\hline \multicolumn{1}{c}{ Variável } & Total & Mercado Formal & Mercado Informal \\
\hline Masculino & & & \\
Feminino & $186(35,2 \%)$ & $129(56,8 \%)$ & $57(18,9 \%)$ \\
\hline \multicolumn{1}{c}{ Idade } & $342(64.8 \%)$ & $98(43,2 \%)$ & $244(81,1 \%)$ \\
\hline $1^{\circ}$ Quartil & $<25$ & $<23$ & $<27$ \\
$2^{\circ}$ Quartil & $26-37$ & $24-35$ & $28-37$ \\
$3^{\circ}$ Quartil & $38-49$ & $36-50$ & $38-48$ \\
$4^{\circ}$ Quartil & $>50$ & $>51$ & $>49$ \\
\hline \multicolumn{1}{c}{ Renda } & & & \\
\hline $1^{\circ}$ Quartil & $2-3$ & $<2$ & $1,5-3$ \\
$2^{\circ}$ Quartil & $3-5,25$ & $2-4$ & $3-4$ \\
$3^{\circ}$ Quartil & $>5,25$ & $7-6,50$ & $>4$ \\
$4^{\circ}$ Quartil & & $>6.50$ & \\
\hline \multicolumn{1}{c}{ Escolaridade } & $5(0,9 \%)$ & & $5(1,7 \%)$ \\
\hline Analfabeto & $88(16,7 \%)$ & $29(12,9 \%)$ & $59(19,6 \%)$ \\
Ensino Fundamental Incompleto & $63(11,(\%)$ & $22(9,7 \%)$ & $41(13,6 \%)$ \\
Ensino Fundamental Completo & $37(7,0 \%)$ & $21(9,3 \%)$ & $16(5,3 \%)$ \\
Ensino Médio Incompleto & $226(42,8 \%)$ & $76(33,5 \%)$ & $150(49,8 \%)$ \\
Ensino Médio Completo & $45(8,5 \%)$ & $36(15,9 \%)$ & $9(3,0 \%)$ \\
Superior Incompleto & $60(11,4 \%)$ & $43(18,9 \%)$ & $17(5,6 \%)$ \\
Superior Completo & $4(0,8 \%)$ & - & $4(1,3 \%)$ \\
Missing & & & \\
\hline
\end{tabular}

Fonte: elaborado pelos autores.

Por conseguinte, foi aplicada a técnica estatística de análise fatorial exploratória com a escala de valores de compra. Usando o critério de extração com base no valor próprio maior que 1 , observou-se, no entanto, que duas questões, HED1 e UTI4, apresentavam baixa comunalidade, abaixo de 0,5 e pouca aderência aos seus respectivos constructos, com carga fatorial inferior a 0,5 (HAIR et al., 2005). Dessa forma, decidiu-se por excluir as variáveis da análise. Após a retirada dos itens, foi possível observar que a questão UTI6 não apresentou aderência a nenhum dos dois construtos examinados na pesquisa. Igualmente, a variável foi retirada. Cumpre salientar que tais variáveis também foram retiradas em outros estudos uma vez que tais questões associam-se, semanticamente, a fatores outros que destoam das acepções teóricas facultadas pelos valores de consumo hedônico e utilitário (LOPES et al., 2010). Após a exclusão das variáveis, a escala agrupou-se eficazmente em dois fatores, como é possível visualizar na Tabela 2, a seguir. 
Tabela 2 - Matriz de componentes rotacionada - Valores de compra

\begin{tabular}{|l|c|c|}
\hline \multicolumn{1}{|c|}{ Valores } & \multicolumn{2}{c|}{ Valores } \\
\cline { 2 - 3 } & Hedônico & Utilitário \\
\hline Eu me diverti fazendo esta compra & 0,691 \\
Comparando com outras coisas que eu poderia ter feito, o tempo gasto & 0,681 \\
comprando este produto foi muito mais agradável. & 0,663 \\
Esqueci os meus problemas enquanto estive no mercadinho. & 0,794 \\
Fazer esta compra foi uma verdadeira distração pra mim. & 0,806 & \\
Estar no Mercadinho foi um jeito muito agradável de passar o tempo. & 0,731 & \\
A busca por este produto me deu um grande prazer. & & 0,601 \\
Eu fui eficiente ao fazer estac compra. & & 0,843 \\
Eu gastei apenas o tempo necessário para fazer esta compra. & & 0,821 \\
Eu fiz esta compra com rapidez. & 33,076 & 23,183 \\
Foi fácil fazer esta compra porque eu sabia exatamente o que eu queria \\
comprar.
\end{tabular}

Fonte: elaborada pelos autores

Utilizando-se a rotação Varimax e o critério de autovalores superiores a 1 (HAIR et al., 2005), foram obtidos os dois fatores, hedônico e utilitário, que, em conjunto, explicaram 56,259\% da variância total. A estrutura erigida pela análise fatorial apresentou um grau de explicação dos dados adequado, representado pelo índice $\mathrm{KMO}(0,817)$, que, segundo Hair et al. (2005), índices acima de 0,7 apresentam resultados satisfatórios. De forma semelhante, o teste de esferacidade de Barlett também se revelou satisfatório $(p=0,000)$, uma vez que alcançou valores menores do que 0,05 (HAIR et al., 2005). Quanto à confiabilidade, acessada mediante o teste alpha de Cronbach, os dois construtos apresentaram índices satisfatórios: $\alpha=0,824$ para o primeiro fator, que representa o valor de compra hedônico e $\alpha=0,748$ para o segundo fator, que representa o valor de compra utilitário (HAIR et al., 2005). Segundo
Malhotra (2001), construtos que apresentam alpha superior a 0,7 possuem consistência interna satisfatória.

Em ato contínuo, após a construção, por meios dos dados auferidos na pesquisa, dos construtos hedônico e utilitário, utilizando-se a técnica estatística análise fatorial exploratória, foram realizados os testes de diferença de variâncias entre os dois ambientes pesquisados, o pequeno varejo e a feira livre. Na Tabela 3, a seguir, apresentam-se os principais dados descritivos do teste ANOVA executado. 
Tabela 3 - Dados descritivos do teste ANOVA

\begin{tabular}{|c|c|c|c|c|c|c|c|c|c|}
\hline & & \multirow[t]{2}{*}{$\mathbf{N}$} & \multirow[t]{2}{*}{ Média } & \multirow{2}{*}{$\begin{array}{l}\text { Desvio } \\
\text { padrão }\end{array}$} & \multirow{2}{*}{$\begin{array}{c}\text { Erro } \\
\text { padrão }\end{array}$} & \multicolumn{2}{|c|}{$\begin{array}{l}\text { Intervalo de confiança de } \mathbf{9 5 \%} \\
\text { para média }\end{array}$} & \multirow[t]{2}{*}{ Mínimo } & \multirow[t]{2}{*}{ Máximo } \\
\hline & & & & & & Limite inferior & Limite superior & & \\
\hline \multirow{3}{*}{$\begin{array}{c}\text { Fator } \\
\text { Hedônico }\end{array}$} & Feira & 301 & 0,1893 & 0,8430 & 0,0485 & 0,0937 & 0,2849 & $-2,9955$ & 1,5534 \\
\hline & Peq. varejo & 227 & $-0,2511$ & 1,1302 & 0,0750 & $-0,3989$ & $-0,1032$ & $-3,0464$ & 1,1372 \\
\hline & Total & 528 & $0 \mathrm{E}-7$ & 1,0000 & 0,0435 & $-0,0854$ & 0,0854 & $-3,0464$ & 1,5534 \\
\hline \multirow{3}{*}{$\begin{array}{l}\text { Fator } \\
\text { Utilitário }\end{array}$} & Feira & 301 & $-0,4141$ & 1,0230 & 0,0589 & $-0,5302$ & $-0,2981$ & $-3,0989$ & 1,2618 \\
\hline & Peq. varejo & 227 & 0,5491 & 0,6411 & 0,0425 & 0,4653 & 0,6330 & $-2,8051$ & 1,2858 \\
\hline & Total & 528 & $0 \mathrm{E}-7$ & 1,0000 & 0,0435 & $-0,0854$ & 0,0854 & $-3,0989$ & 1,2858 \\
\hline
\end{tabular}

Fonte: elaborado pelos autores.

Como é possível observar, mediante as informações disponibilizadas na Tabela 3 , as médias dos dois ambientes, quando avaliado somente o fator hedônico, apresentam sinais distintos, com a feira alcançando valores positivos e o pequeno varejo atingindo valores negativos. Tal resultado indica que os consumidores da feira apresentaram uma média de respostas com inclinações mais hedônicas do que as demonstradas pelos consumidores do pequeno varejo. Por conseguinte, observa-se que quando examinado o fator utilitário os sinais das médias relativas aos ambientes se invertem; os consumidores do pequeno varejo passam a apresentar uma inclinação utilitária mais acentuada do que os consumidores da feira.

Os resultados aferidos vão ao encontro das acepções teóricas salientadas na literatura pertinente a feiras livres, uma vez que, de acordo com as médias apresentadas, os consumidores da feira possuem inclinações mais salientes ao consumo hedônico/festivo do que ao consumo utilitário/racional, corroborando as pesquisas realizadas por Belk, Sherry e Wallendorf (1988), Sherry (1990a, 1990b). Tais resultados também são evidenciados por Menezes (2005), porquanto, segundo o autor, a dimensão hedônica de consumo emerge na feira por meio da interação do consumidor com o amálgama de cores, sons, produtos e pessoas presentes na feira. Sherry (1990a, 1990b) acrescenta, ademais, que a pluralidade de pessoas, produtos e eventos ocorrendo simultaneamente no espaço da feira livre seriam capazes de criar um senso de empolgação desmedida no consumidor, municiado pela sensação de liberdade por se transitar em um espaço a céu aberto, bem como pela oportunidade de se observar e se barganhar uma infinidade de itens disponíveis à troca ou à venda.

Conforme demonstrado, ademais, os resultados da pesquisa ratificam as acepções de Belk, Sherry e Wallendorf (1988), os quais contestam a uniformidade no comportamento de consumidores de mercados informais. Segundo os autores, no mercado informal o comportamento do consumidor seria mais perigoso ou excitante e menos padronizado; por outro lado, no mercado formal, a relação de compra e venda, intermediada por empresas e clientes, seria mais fria e previsível, o que atenuaria a percepção hedônica de consumo nesses ambientes.

De forma análoga, os resultados, referentes ao comportamento do consumidor à luz dos valores de consumo hedônico e utilitário, corroboram os aportes teóricos 
levantados na literatura de pequeno varejo, porquanto os respondentes tenham apresentado, diferentemente do que demonstraram os consumidores da feira, uma dimensão de consumo predominantemente utilitária (HERNANDEZ, 2009; SAMPAIO et al., 2009). Tais resultados se devem, principalmente, segundo Batra e Ahtola (1991) e Babin, Darden e Griffin (1994), a uma orientação voltada à consecução de uma compra com eficiência, com centralidade na satisfação de uma necessidade concreta. Dessa forma, os consumidores se deslocariam para um estabelecimento de pequeno varejo com o intuito de realizarem uma compra com rapidez, sem grandes deslocamentos e buscando sempre o menor preço dos produtos (PARENTE; KATO, 2001; LUPPE; ANGELO, 2010).

Vale destacar que, embora seja possível uma mesma pessoa apresentar inclinações tanto ao valor hedônico quanto ao utilitário (BABIN; DARDEN; GRIFFIN, 1994; LOPES et al., 2010), os resultados revelaram que as médias das respostas totais dos entrevistados em ambos os contextos apresentaram sinais contrários, uma vez que as médias pertinentes aos fatores hedônico e utilitário na feira alcançaram valores positivo e negativo, consecutivamente, e, por outro lado, as médias das dimensões de consumo no pequeno varejo atingiram, em ordem, valores negativo e positivo. Tais resultados fortalecem as pressuposições levantadas na literatura de uma marcada dimensão hedônica presente no contexto de feiras livres e uma distinta característica utilitária presente em pequenos varejos.

Contudo, cumpre observar se a divergência entre as médias apresentadas pelos consumidores nos dois ambientes de pesquisa é significantemente destoante. Os resultados do teste ANOVA são exibidos na Tabela 4, a seguir.

Tabela 4 - Resultados do teste ANOVA

\begin{tabular}{ll|c|c|c|c|c}
\hline & $\begin{array}{c}\text { Soma dos } \\
\text { Quadrados }\end{array}$ & df & $\begin{array}{c}\text { Média dos } \\
\text { Quadrados }\end{array}$ & F & p \\
\hline \multirow{3}{*}{ Fator Hedônico } & Entre Grupos & 25,109 & 1 & 25,109 & 26,315 & $0,000 * * *$ \\
& Nos grupos & 501,891 & 526 & 0,954 & & \\
& Total & 527,000 & 527 & & & \\
\hline \multirow{2}{*}{ Fator Utilitário } & Entre Grupos & 120,092 & 1 & 120,092 & 155,240 & $0,000 * * *$ \\
& Nos grupos & 406,908 & 526 & 0,774 & & \\
& Total & 527,000 & 527 & & & \\
\hline
\end{tabular}

*** Significante a $1 \%$.

Fonte: elaborado pelos autores.

Os resultados revelados pela Tabela 4 evidenciam uma divergência de variância significante entre os dois ambientes de pesquisa ao se avaliar o fator hedônico de consumo, pois, segundo Malhotra (2001), resultados abaixo de 0,05 demonstram diferença na média dos construtos em análi- se. Alinhado com os dados analisados anteriormente, os quais demonstravam uma inclinação positiva e mais forte ao valor de consumo dos consumidores da feira, é possível corroborar a hipótese H1 estruturada inicialmente, a qual aduz que os consumidores de feiras livres possuem um valor de 
consumo hedônico significantemente mais forte do que os consumidores de pequenos varejos. Por meio do Gráfico 1, a seguir, é possível visualizar a diferença de variância entre os dois locais de pesquisa.

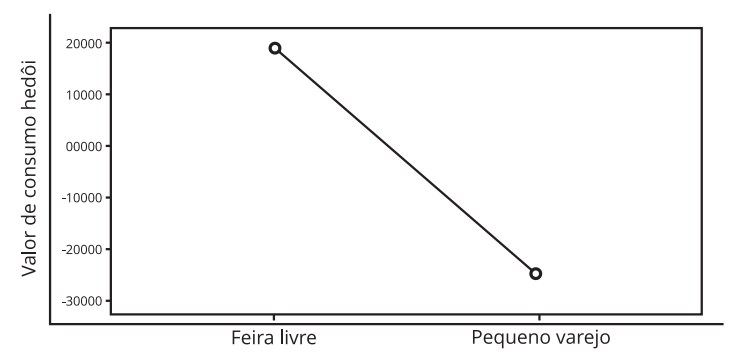

Gráfico 1 - Médias do valor hedônico de consumo entre os dois ambientes de compra Fonte: elaborado pelos autores.

Por meio da análise do Gráfico 1, a divergência de variâncias entre os dois ambientes de compra apresenta-se de forma mais clara. O gráfico demonstra uma grande distorção entre as médias apresentadas pelos consumidores dos dois locais, o que resultou em uma diferença significativa entre as variâncias apresentadas por eles. Como é possível observar, a média dos entrevistados da feira, ao se isolar somente o valor hedônico de consumo, alcançou valores significativamente maiores do que os atingidos pelos respondentes do pequeno varejo.

De forma diametralmente oposta, entretanto, revelaram-se os dados pertinentes ao valor de consumo utilitário, como é possível observar no Gráfico 2, a seguir.

Como elucidado no gráfico, há uma diferença expressiva no comportamento dos consumidores dos dois locais de pesquisa, atinente à dimensão utilitária de compra. Com efeito, é possível observar que o valor de compra utilitário predomina nos respondentes do pequeno varejo, uma vez que alcançaram índices significante- mente maiores do que os entrevistados da feira.

Quanto à comparação entre o comportamento de consumidores de pequenos varejos e feiras livres cabe ser feita uma observação. Estudos que realizem exames comparativos dos públicos dos dois locais, avaliando-se os valores de consumo hedônico e utilitário, não foram encontrados na literatura. Dessa forma, embora tenha sido possível erigir as hipóteses por meio de um levantamento do arcabouço teórico concernente aos dois ambientes e aos mercados nos quais se inserem, não foi possível corroborar pressuposições de trabalhos que evidenciassem, de fato, que um ambiente tem um valor de consumo mais forte do que o outro. Destarte, como contribuição adicional deste trabalho, destaca-se a demonstração de que em ambientes informais os consumidores apresentam uma predominância do valor de compra hedônico, em detrimento do valor utilitário de compra; ao passo que em ambientes formais os consumidores orientam-se, majoritariamente, pela dimensão de compra utilitária. Vale destacar, no entanto, que os valores de consumo podem coexistir em um mesmo indivíduo; tais resultados baseiam-se, portanto, na média geral apresentada pelos consumidores.

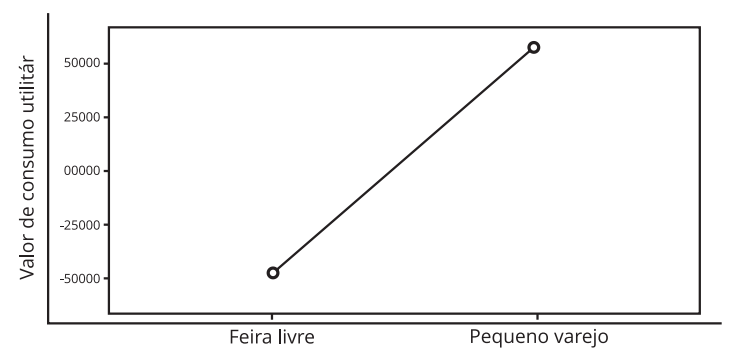

Gráfico 2 - Médias do valor utilitário de consumo entre os dois ambientes de compra

Fonte: elaborado pelos autores. 


\section{CONSIDERAÇÕES FINAIS}

O objetivo de se analisar o comportamento de consumo de indivíduos em mercados formais e informais, inicialmente proposto para orientar o direcionamento da pesquisa, foi alcançado. Para tal, foram examinados e comparados os comportamentos de consumo, à luz da teoria dos valores de compra hedônico e utilitário, de clientes de um pequeno varejo, representante, nesta pesquisa, dos mercados formais, e de uma feira livre, a qual representa os mercados informais.

Os resultados da pesquisa corroboraram as hipóteses construídas no levantamento bibliográfico. A comprovação da hipótese H1, a qual aduz que "os consumidores de feiras livres possuem um valor de consumo hedônico significantemente mais forte do que os consumidores de pequenos varejos", indica que a dimensão lúdica e emotiva de compra dos consumidores de feiras destaca-se, em detrimento dos clientes de pequenos varejos, como orientação preponderante. Do mesmo modo, a hipótese $\mathrm{H} 2$, "os consumidores de pequenos varejos possuem um valor de consumo utilitário significantemente mais forte do que os consumidores de feiras livres", também foi comprovada, salientando a forma objetiva e pragmática de se desempenhar a atividade de compra por parte dos consumidores de pequenos varejos.

A pesquisa revelou que os consumidores de pequenos varejos, representantes do mercado formal neste estudo, possuem, hegemonicamente, inclinações utilitárias de compra. Dessa forma, cabe aos administradores de tais estabelecimentos manterem os fatores utilitários de compra como elementos higiênicos, ou seja, essenciais para a manutenção da demanda e satisfação dos clientes. Para tal, não prescinde oferecer sempre produtos com preços baixos, em um local estratégico acessível, com um grande e sempre disponível sortimento de produtos, com um ambiente organizado, atendimento eficaz, disponibilizando uma atividade de compra com rapidez, sem filas ou atrasos em demasia, dentre outros.

Por outro lado, os consumidores de feiras livres, representantes do mercado informal nesta pesquisa, apresentaram, predominantemente, inclinações hedônicas de compra. Destarte, seria interessante aos feirantes e órgãos públicos responsáveis por tais locais, intensificarem esforços na manutenção das características hedônicas das feiras, tais como: relacionamento interpessoal de amizade com os clientes, oferta de produtos com valor simbólico agregado, ambiente chamativo e acolhedor, organização de festivais culturais, manutenção da identidade étnica, dentre outros.

Deve-se destacar, ademais, que ambos os ambientes possuem muito que aprender um com o outro. Enquanto que à feira cabe a inserção de elementos marcadamente utilitários que facultem a permanência e compra em seu interior com facilidade e segurança, como higiene, organização dos espaços, vigilância e infraestrutura tanto interna quanto nas cercanias, aos pequenos varejos é necessário que se incremente os fatores hedônicos do ambiente de loja, proporcionando maior conforto e prazer em se permanecer no interior de tais estabelecimentos. Para tal, faz-se mister maior preocupação com os aspectos estéticos do local, bem como a transgressão do simples e frio contato formal com os clientes, intensificando-se o relacionamento de amizade entre funcionários e fregueses. Ademais, a valorização de elementos hedônicos auxiliaria na criação de um clima agradável no 
estabelecimento, contribuindo para a fidelização dos clientes, assim como ocorre nas feiras livres, e uma maior permanência no interior da loja, fato que, em geral, incorre em maior volume de compras.

Como limitações da pesquisa, aponta-se o fato de que, embora tenha sido um estudo realizado com mais de 500 respondentes, a pesquisa não se caracteriza como uma amostragem probabilística. Ao contrário do que ocorreu com o pequeno varejo, onde foi possível colher os dados de grande parte dos seus clientes, a ausência de dados da feira impossibilitaram um levantamento probabilístico no local. Outro fator limitante da pesquisa foi o fato de ter sido realizada somente com um único representante de cada mercado, formal e informal. A expansão da pesquisa a outros locais, efetuando-se a comparação realizada neste estudo de forma similar, seria capaz de aumentar a generalização dos resultados obtidos.

Para pesquisas futuras, indica-se a replicação do estudo substituindo-se por empreendimentos formais que possuam diversas lojas, em detrimento de uma única loja, como realizado nesta pesquisa. A aplicação da escala de valores de consumo hedônico e utilitário nesses locais, como shopping centers e mercados populares, seria interessante, uma vez que tais estabelecimentos possuem uma ambientação de consumo semelhante às feiras livres, apresentando características como: uma variedade enorme de produtos, uma grande quantidade de pessoas, uma profusão de cores e sons, dentre outros. Tal comparação trará uma maior compreensão sobre o fenômeno de consumo.

\section{THE BEHAVIOR OF THE CONSUMER IN THE INFORMAL MARKETS: THE VALUES OF THE HEDONIC AND UTILITARIAN PURCHASES}

\section{SUMMARY}

Although there are large amount of works aimed at the study of formal markets, little research focus on the analysis of informal markets. Even more insipid is the theoretical body composed of the studies concerning the comparison of these environments. Thus, this study aimed at analyzing and comparing the behavior of consumers of formal and informal markets, represented by a small retail shop and a free fair, respectively, in the light of the hedonic and utilitarian shopping values. For that matter, the values of consumer purchase of both environments shall be examined and compared. By means of the application of a survey, the values of the consumer purchase of these environments were examined using statistical techniques AFE and ANOVA, compared to such values. The results obtained corroborate the hypotheses raised, because the research shows that the consumers of formal markets have utilitarian shopping values significantly higher than the ones presented by regular users of informal markets. On the other hand, the consumers of the informal markets have demonstrated hedonic shopping value significantly higher than the customers of formal markets.

Keywords: Formal and informal markets. Consumer behavior. Hedonic and utilitarian shopping value. 


\section{REFERÊNCIAS}

APPLEBAUM, W. Methods for determining store trade areas, marketing penetration and potential sales. Journal of Marketing Research, v.3, p.127-141, may 1996.

ARBEX, M.; FREGUGLIA, R.; CHEIN, F. Informal economy and spatial mobility: are informal workers economic refugees? Journal of Economic Studies, v. 40, n. 5, p. 671-685, 2013.

BABIN, B.; DARDEN, W.; GRIFFIN, M. Work and/or Fun: measuring Hedonic and Utilitarian Shopping Value. Journal of Consumer Research, v. 20, n. 4, p. 644 656, 1994.

BANCO MUNDIAL. The world development report. Washington, D. C.: The World Bank Group, 2000.

BATRA, R.; AHTOLA, O. Measuring the Hedonic and Utilitarian sources of consumer attitudes. Marketing Letters, v. 2, n. 2, p. 159-170, 1991.

BAURDILLARD, J. A sociedade de consumo. Lisboa: Edições 70, 2002.

BELK, R.; SHERRY, J.; WALLENDORF, M. A naturalistic Inquiry into buyer and seller behavior at a Swap Meet. Journal of Consumer Research,v. 14, n. 4, p. 449 470, 1988.
BRITO, E. P.; VIEIRA, V. A.; ESPARTEL; L. B. A pesquisa na área do varejo: reflexões e provocações. RAE - Revista de Administração de Empresas, v. 51, n. 6, p. 522-527, 2011.

FÁVERO, L. P. Atuação em tempos de crise e competitividade acirrada. São Paulo: FIA-FEA/USP, 2004.

FEIJÓ, F. R.; BOTELHO, D. Efeito dos fatores de merchandising nas vendas do varejo. RAE - Revista de Administração de Empresas, São Paulo, v. 52, n. 6, p. 628642, 2012.

GATTO, S. L'atmosfera del punto vendita quale strumento di differenziazione dell'insegna: una verifica empirica delgli effetti della variabile olfativa. In: CONGRESSO INTERNAZIONALE "LE TENDENZE DEL MARKETING", 2002, Venezia. Anais... Venezia: Università Ca' Foscari Venezia, 2002. p. 1-25.

GOTO, H.; MANO, Y. Labor market competitiveness and the size of the informal sector. Journal of Popular Economics, v. 25, p. 495-509, 2012.

HAIR J. F. et al. Análise Multivariada de Dados. 5. ed. Porto Alegre: Bookman, 2005.

HAUSMAN, A. A multi-method investigation of consumer motivations in impulse buying behavior. Journal of Consumer Marketing, v. 17, n. 5, p. 403-426, 2000. 
HERNADEZ, J. M. Foi Bom Para Você? uma comparação do valor hedônico de compras feitas em diferentes tipos de varejistas. RAM - Revista De Administração Mackenzie, v. 10, n. 2, p.11-30, 2009.

HOLBROOK, M; HIRSCHMAN, E. The experiential aspects of consumption: consumer fantasies, feelings, and fun. Journal of Consumer Research,v. 9, n. 2, p. 132140, 1982.

LEVY, M; WEITZ, B. A. Retailing management. Boston: McGraw-Hill, 2004.

LOPES, E. et al. Valores de compra hedônico e utilitário: duas aplicações no varejo especializado. In: ENCONTRO NACIONAL DA ASSOCIAÇÃO NACIONAL DOS PROGRAMAS DE PÓS-GRADUAÇÃO EM ADMINISTRAÇÃO, 34., 2010, Rio de Janeiro. Anais... Rio de Janeiro: ANPAD, 2010. p. 1-17

LOUREIRO, P. R.; ARAUJO, R. A.; SOUZA, N. A. An evaluation of the Brazilian informal labor market from 1995 to 2008. Journal of Economic Studies, v. 40, n.1, p. 71-87, 2013.

LUKE, N.; MUNSHI, K..; ROSENZWEIG, M. Marriage, networks, and jobs in third world cities. Journal of European Economic Association, v. 2, issue 2-3, p. 437-446, 2004.
LUPPE, M. R.; ANGELO, C. F. As decisões de consumo e a heurística da ancoragem: uma análise da racionalidade do processo de escolha. RAM - Revista de Administração Mackenzie,v. 11, n. 6, p. 82-106, 2010.

MAlHotra, N. K. Pesquisa de Marketing: uma orientação aplicada. 3. ed. Porto Alegre: Bookman, 2001.

MENEZES, V. As feiras-livres em Fortaleza - retrato da polissemia urbana. 2005. 130 f. Dissertação (Mestrado em Geografia) - Universidade Estadual do Ceará, Fortaleza, 2005.

OZUDURU, B. H.; VAROL, C.; ERCOSKUN, O. Y. Do shopping centers abate the resilience of shopping streets? The co-existence of both shopping venues in Ankara, Turkey. Cities, v. 36, p. 145-157, 2012. Disponívelem: $<$ http://dx.doi.org/10.1016/j.cities.2012.10.003>. Acesso em: 30 abr. 2014.

PANDOLFO, M. Feira de São Cristovão: a reconstrução do nordestino num mundo de paraibas e nortistas. 1987. 209 f. Dissertação (Mestrado em Educação) - Fundação Getúlio Vargas, Rio de Janeiro, 1987.

PARENTE, J. G.; KATO, H. T. Área de influência: um estudo no varejo de supermercados. RAE - Revista de Administração de Empresas, v.41, n. 2, p. 46-53, abr./jun. 2001. 
PETRESCU , M.; BHATLI, D. Consumer behavior in flea markets and marketing to the Bottom of the Pyramid. Journal of Management Research, v. 13, n. 1, p. 5563, 2013.

PIRENNE. H. As cidades na idade média. Lisboa: Europa-América, 1997.

RAJAGOPAL. Coexistence and conflicts between shopping malls and street markets in growing cities: analysis of shoppers' behavior. Journal of Retail \& Leisure Property, v. 9, n. 4, p. 277-301, 2010a.

RAJAGOPAL. Street markets influencing urban consumer behavior in Mexico. Latin American Business Review, v. 11, p. 77110, 2010b.

ROCHA, E. Culpa e Prazer: imagens do consumo na cultura de massa. Comunicação, Mídia e Consumo, v. 2, n. 3, p. 123138, 2005.

SAMPAIO, C. et al. Fatores visuais de design e sua influência nos valores de compra do consumidor. RAE - Revista de Administração de Empresas, v. 49, n. 4, out./ dez., 2009.

SHERMAN , E.; MCCROHAN, K.; SMITH, J. D. Informal retailing: an analysis of products, attitudes, and expectations. Advances in Consumer Research, v. 12, n.1, p. 204-208, 1985.
SHERRY, J. F. Dealers and dealing in a periodic market: informal retailing in ethnographic perspective. Journal of retailing, v. 66, n. 2, p. 174-200, 1990a.

SHERRY, J. F. Sociocultural Analysis of a Midwestern American Flea Market reviewed. Journal of Consumer Research, v. 1, n. 1, p. 13-30, 1990b.

SCHNEIDER, F.; ENSTE, D. H. The shadow economy: an international survey. Cambridge: Cambridge University Press, 2002.

TERRA, E. A. A. Classificação do Varejo: um estudo sobre diferentes abordagens. São Paulo: FIA-FEA/USP, 2004.

ULYSSEA, G. Informalidade no mercado de trabalho brasileiro: uma resenha da literatura. Revista de Economia Política, v. 26, n. 4, p. 596-618, 2006.

WAHBA, J.; ZENOU, Y. Density, social networks and job search methods: theory and application to Egypt. Journal of Development Economic, v. 78, n. 2, p. 443-473, 2005.

ZORRILLA, P. Nuevas tendencias em merchandising: generar experiencias para conquistar emociones y fidelizar clientes. Distribución y Consumo, p. 13-20, sept./ oct., 2002. 